\title{
Microencapsulation of Photochromic Solution with Polyurea by Interfacial Polymerization
}

\author{
Yuhua Zhang, Xi Zhang, Yurong Yan * and Zhonghua Chen *
}

School of Material Science and Engineering, South China University of Technology, Guangzhou 510640, China; zhangyuhua_scut@hotmail.com (Y.Z.); zhxxi333@163.com (X.Z.)

* Correspondence: yryan@scut.edu.cn (Y.Y.); cezhchen@scut.edu.cn (Z.C.)

Citation: Zhang, Y.; Zhang, X.; Yan, Y.; Chen, Z. Microencapsulation of Photochromic Solution with Polyurea by Interfacial Polymerization. Polymers 2021, 13, 3049. https:// doi.org/10.3390/polym13183049

Academic Editors: Binh Thanh Mai, Eduardo Ruiz-Hernandez, Kwon Taek Lim and Nisarg Soni

Received: 10 August 2021

Accepted: 7 September 2021

Published: 9 September 2021

Publisher's Note: MDPI stays neutral with regard to jurisdictional claims in published maps and institutional affiliations.

Copyright: (c) 2021 by the authors. Licensee MDPI, Basel, Switzerland. This article is an open access article distributed under the terms and conditions of the Creative Commons Attribution (CC BY) license (https:// creativecommons.org/licenses/by/ $4.0 /)$.

\begin{abstract}
Photochromic materials are interesting materials because of their color-changing property under UV light and visible light irradiation. However, they are vulnerable to many factors, such as $\mathrm{pH}$ oxygen, ion, solvent, etc. because of the unsaturated bonds existing on the photochromic molecular. Microencapsulation of the photochromic materials can separate them from the surroundings. Here, photochromic microcapsules using 3,3-Diphenyl-3H-naphtho[2,1-b] pyran (NP)/solution as core and polyurea as shell via interfacial polymerization were prepared, and bis(2,2,6,6-tetramethyl-4piperidinyl)sebacate (HALS 770) was used as photostabilizer. Fourier transform infrared spectroscopy (FTIR), a laser particle size analyzer, a scanning electron microscope (SEM), a thermogravimetric analyzer and an ultraviolet-visible spectrophotometer were used for characterization. The results showed that the microcapsules had a uniform particle size of about $0.56 \mu \mathrm{m}$ when the percentage of the oil phase (core) in the emulsion was less than $15 \%$, the addition amount of the emulsifier was $0.4 \%$, and the stirring rate was $1800 \mathrm{r} / \mathrm{min}$. The microcapsules showed better performance in thermal stability when the core/shell ratio was 1:1. The photostabilizer had little impact on the color-changing property of the microcapsule, but it could protect the microcapsules from UV light radiation aging.
\end{abstract}

Keywords: photochromic material; photochromic property; microcapsules; photostabilizer; interfacial polymerization; polyurea

\section{Introduction}

Photochromic materials are compounds that can change color when exposed to UV light or visible light [1]. The characteristic of photochromic materials has attracted great attention among researchers in different fields, such as optical anti-counterfeiting [2,3], smart fiber [4], information storage [5], color-changing film [6], and color-changing glass [7,8]. To make better use of photochromic materials, researchers have made a lot of effort to synthesize or modify photochromic molecules. Vyasamudri et al. [9] prepared colorless 2,6-dioxabicycles and 2,8-dioxabicycles using the method of divergent synthesis. They found the 2,6-dioxabicycles synthesized by base catalysis could turn red when exposed to UV light. Helmy et al. [10] designed a new kind of photochromic molecule with properties of good fatigue resistance and color-switching under visible light. It is significant in many fields, for example, biosensors and targeted delivery systems. Researchers brought photochromic groups or molecules into the main chain or substituted side group of polymers via covalent bonds, and designed modified functional polymers characterized by photochromic properties [11-15].

Compared to inorganic photochromic material, organic photochromic materials respond quickly to light and can restore to their original state rapidly without light [16], which brings them more interest in use. However, unsaturated bonds typically present on the organic molecule of the photochromic materials which are sensitive to $\mathrm{pH}$, oxygen, ion, solvent etc. leading to a shortened service life in actual application [17]. In addition, some organic photochromic materials show better photochromic properties only when dissolved 
in a specific solvent [18-20]. Thus, in order to use them practically, we should separate them from their surroundings and keep them in shape. Microencapsulation is an effective way to make this a reality. As a relatively mature technology, microencapsulation has been applied in many fields [21-25]. The most common ones are phase change material microencapsulation and drug sustained-release microencapsulation [26-28]. There is also some literature about microencapsulation of photochromic materials [29-32]. Feczkó et al. [29] prepared a kind of photochromic nanocapsule using poly (methyl methacrylate) and ethyl cellulose as shell and spirooxazine solution as core by the emulsion-solvent evaporation method. They found that the color changed more intensely and lasted longer compared to the solution of the same spirooxazine in an organic solvent. However, there exists a large amount of solvent evaporation in the preparation of the microcapsules, which is not environmentally friendly, so it needs further treatment of the solvent vapor. Zhou et al. [30] microencapsulated photochromic compounds with melamine-formaldehyde successfully and applied them to textile. The lifetime of photochromic compounds after encapsulation could extend 10 times compared with before encapsulation under continuous UV. However, melamine-formaldehyde will release formaldehyde when used, which is harmful to human health. Polyurea is a promising wall material in microcapsules due to its chemical stability, acid and alkali resistance, and solvent resistance. Usually, polyurea shell microcapsules were obtained via interfacial polymerization. The polyfunctional isocyanate was introduced to the oil phase and the polyfunctional amine was added to the water phase, then a condensation reaction occurred at the interface of the oil and water phases [33]. Polyurea has been used to encapsulate butyl stearate containing spirooxazine to form reversible photochromic energy storage microcapsules by Sun et al. [34].

Since most microcapsules are designed with polymers as shells, which decompose easily when exposed to UV light [35], the microcapsule of photochromic material may suffer aging and decomposition during their use. Moreover, the photochromic materials also suffer from photooxidation during their color-changing under UV light irradiation. Photostabilizer can quench the excited state of the molecule or group excited by UV rays and return it to the ground state, eliminating or slowing down the possibility of photoredox reaction [36]. It is always used in polymer products to reduce the damage from UV light. However, to the best of our knowledge, the reports about photostabilizer used in microcapsules are rare. In this paper, we tried to microencapsulate a kind of photochromic compound with polyurea by simple interfacial polymerization. We creatively addicted bis(2,2,6,6-tetramethyl-4-piperidinyl)sebacate as photostabilizer to the microcapsules. Particle size distribution, morphology, thermo-stability, and the photochromic property of the microcapsules were investigated.

\section{Materials and Methods}

\subsection{Materials}

3,3-Diphenyl-3H-naphtho[2,1-b] pyran (NP) (purity >98\%) purchased from Aladdin Reagent (Shanghai) Co., Ltd. (Shanghai, China) was used as photochromic material; S1000 (a mixture of non-volatile hydrocarbons) supplied by Xinxiang Bailu Chemical Fiber Group Co., Ltd. (Xinxiang, China) was used as the solvent of photochromic material; isophorone diisocyanate (IPDI) (purity $>99 \%$ ) bought from Aladdin Reagent (Shanghai) Co., Ltd. and diethylenetriamine (DETA) (purity $>98 \%$ ) provided by Fortune (Tianjin) Chemical Reagent Co., Ltd. (Tianjin, China) were used as monomers of the polymer shell; bis(2,2,6,6-tetramethyl-4-piperidinyl)sebacate (HALS 770) (purity >99\%) supplied by Aladdin Reagent (Shanghai) Co., Ltd. (Shanghai, China) was employed as photostabilizer; Tween 80 (Reagent Grade) purchased from Aladdin Reagent (Shanghai) Co., Ltd. (Shanghai, China) was used as emulsifier. All the materials were used without any further purification.

\subsection{Synthesis of the Photochromic Material Microcapsule}

Microcapsules containing photochromic material were prepared by emulsion interfacial polymerization. Firstly, NP and HALS 770 were dissolved in the solvent at $50^{\circ} \mathrm{C}$ to 
form the photochromic solution, after the solution was cooled to room temperature, IPDI was mixed with it as the oil phase; A certain amount of deionized water and Tween 80 were added to the three-neck flask and stirred mechanically using a high shear mixer to form the aqueous phase; The oil phase was dropped to the aqueous phase slowly under the vigorous stirring of the shear mixer at room temperature; After the completion of the oil phase dripping, it was stirred for $30 \mathrm{~min}$ and then the required emulsion was achieved. The stirring rate was set at $600 \mathrm{r} / \mathrm{min}$ and $10 \%(w / w)$ aqueous solution of DETA was added to the emulsion drop by drop using a constant pressure funnel. The reaction lasted for $4 \mathrm{~h}$ at room temperature and continued for $8 \mathrm{~h}$ at $50^{\circ} \mathrm{C}$. The suspension of microcapsules was achieved after the final $2 \mathrm{~h}$ at $80^{\circ} \mathrm{C}$. Finally, the production was washed by petroleum ether three times and then dried in the fume hood. The microencapsulation process is schematically shown in Figure 1.

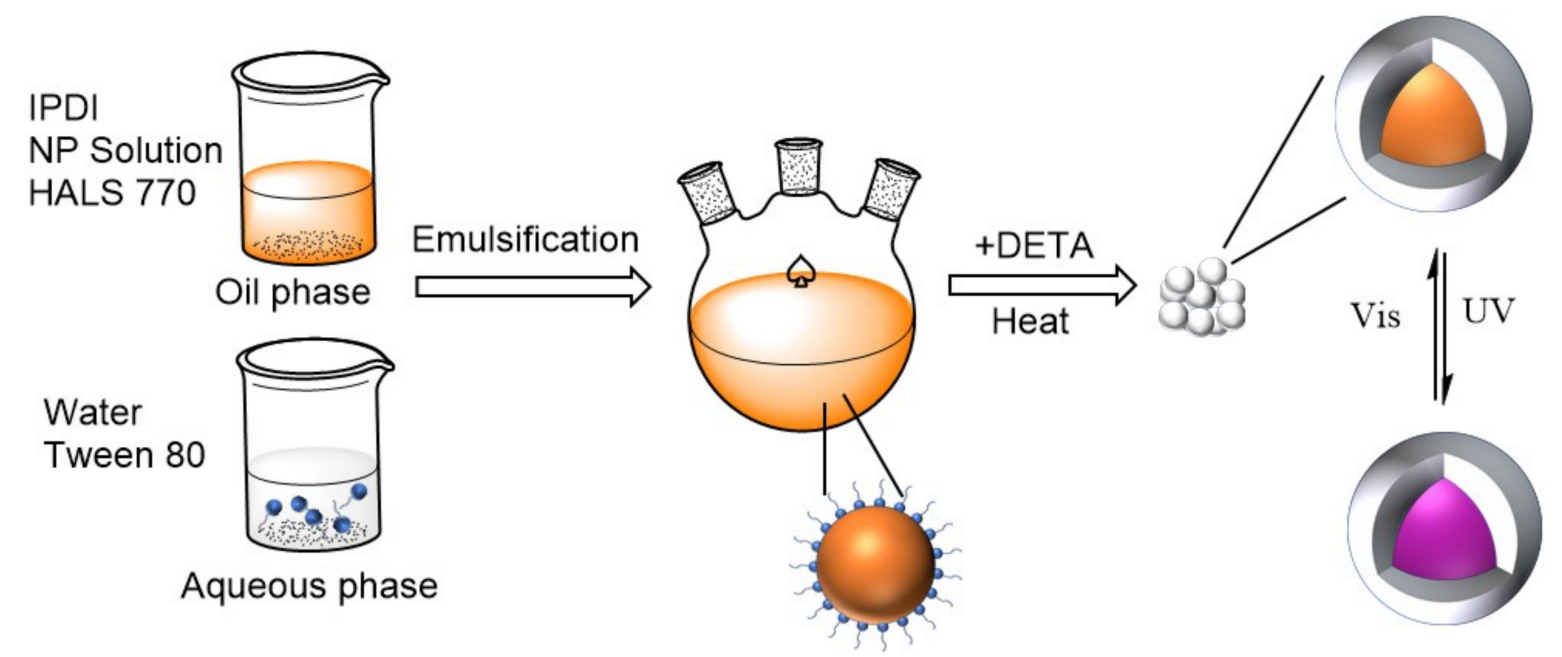

Figure 1. Scheme of the synthesis of the photochromic material microcapsule.

\subsection{Characterization}

2.3.1. Fourier Transform Infrared Spectroscopy (FTIR)

The chemical structure of 3,3-diphenyl-3H-naphtho[2,1-b]pyran (NP) solution and its microcapsule were characterized by FTIR. The spectra of photochromic solution were collected by dropping the liquid on the potassium bromide $(\mathrm{KBr})$ pellets directly, and the spectra of microcapsules were collected by mixing the solid with $\mathrm{KBr}$ pellets. All spectra were obtained via 32 scans from 4000 to $400 \mathrm{~cm}^{-1}$ using an FTIR spectrometer (Bruker Dalton, Tensor II).

\subsubsection{Particle Size and Its Distribution}

The particle size and the distribution of the microcapsules were investigated using a laser particle size analyzer (Beckman Coulter, LS13320). The tested microcapsule was dispersed in deionized water via ultrasonic dispersion by the cell disruptor (Lichen, LCJY88-IIN). Then the particle size and its distribution were measured by dropping the dispersions to the sample chamber of the laser particle size analyzer.

\subsubsection{Surface Features and Morphology}

The surface features and morphology of the microcapsules were observed on a scanning electron microscope (SEM, Holland, NOVA NANOSEM 430). A sprinkle of sample was put on electric conductive adhesive and coated with a layer of platinum to avoid being scorched. 


\subsubsection{Thermostability}

The thermal decomposition temperatures of the microcapsules were analyzed using a thermogravimetric analyzer (TGA, Netzsch, HAAKE400P). We placed 5-10 mg sample of the microcapsule in an alumina crucible and heated it at the rate of $10^{\circ} \mathrm{C} / \mathrm{min}$ from 30 to $600{ }^{\circ} \mathrm{C}$ under $\mathrm{N}_{2}$ atmosphere. The weight of the tested sample lost in different ranges and the temperature points at which the sample started to lose weight were recorded on the curves of TGA.

\subsubsection{Tightness Performance}

The tightness performance of the microcapsules was tested by observing the weight loss of the microcapsules. $10 \mathrm{~g}$ sample of the product was placed in an oven at $80{ }^{\circ} \mathrm{C}$ for $24 \mathrm{~h}$, and the percentages of the remaining mass were recorded every four hours.

\subsubsection{Ultraviolet-Visible (UV-Vis) Absorbance}

The UV-Vis spectra of the microcapsules were performed by an ultraviolet-visible spectrophotometer (Hitachi, Japan, U-3010).

\subsubsection{Photochromic Cycle Test}

The suspensions of the microcapsules were put into a colorless transparent glass screw bottle, then the samples were irradiated by UV light with wavelength of $365 \mathrm{~nm}$ using a flashlight (5 W, Ultra fire, $501 \mathrm{~B})$ for $2 \mathrm{~min}$ and kept in the dark for 10 min alternately.

\subsubsection{UV Accelerated Aging Test}

Microcapsule suspensions were exposed to the UV light $\left(40 \mathrm{~W} / \mathrm{m}^{2}, 340 \mathrm{~nm}\right)$ at a distance of $30 \mathrm{~cm}$ in an ultraviolet spectrum accelerated aging test machine (Q-Lab, QUV/Spray) at $25 \pm 5{ }^{\circ} \mathrm{C}$ for $15 \mathrm{~d}$ [37]. After that, the absorbance at the strongest absorption wavelength $(550 \mathrm{~nm})$ of the microcapsules was measured via a UV-visible spectrophotometer (Hitachi, Japan, U-3010).

\subsubsection{Characterization of Color Change}

The color change of the microcapsules was tested by recording the chromatic aberration $(\Delta \mathrm{E})$ of the microcapsules before and after the irradiation of the UV light.

\section{Results and Discussion}

\subsection{Preparation of the Photochromic Microcapsule}

The photochromic microcapsules were prepared via interfacial polymerization of IPDI and DETA in the emulsion. At first, IPDI in the oil phase was dispersed into the water uniformly to form an O/W emulsion. Subsequently, DETA solution was dropped into the $\mathrm{O} / \mathrm{W}$ emulsion slowly. The $-\mathrm{NCO}$ group can react easily with lots of molecular groups having active hydrogen [38], for example, $-\mathrm{OH},-\mathrm{NH}_{2},-\mathrm{NH}-,-\mathrm{COOH}$. But the reaction rate varies widely. The reactivity of $-\mathrm{NH}_{2}$ is much higher than other groups. Therefore, the $-\mathrm{NH}_{2}$ groups on DETA reacted with $-\mathrm{NCO}$ groups on IPDI immediately at the interface of oil phase and aqueous phase once the DETA solution was added to the emulsion. In order to control the reaction rate of IPDI with DETA, it is significant to slow the speed of DETA's addition. When finishing the addition of DETA, the concentrations of -NCO and $-\mathrm{NH}_{2}$ decreased as the reaction lasted. It was necessary to raise the reaction temperature to $50{ }^{\circ} \mathrm{C}$ to ensure the continued reaction of IPDI with DETA. The shell formed gradually at the surface of the oil phase dispersion as the polymer chains' length increased. In the final stage of the reaction, $-\mathrm{NH}$ - on the polymer chains formed reacted with $-\mathrm{NCO}$ groups on IPDI at a higher temperature of $80^{\circ} \mathrm{C}$, which caused the cross-linking of the polymers. In this process, IPDI might also react with water theoretically because of the - $\mathrm{OH}$ existing on the water molecule. However, the reactivity of $-\mathrm{OH}$ group on water is much lower than that of $-\mathrm{NH}_{2}$ and $-\mathrm{NH}$, so the reaction mainly occurred between IPDI and DETA. 


\subsection{FTIR}

To chemically confirm the component of the microcapsule of the photochromic solution, FTIR Spectrometer was employed to achieve the spectra of photochromic solution, blank polyurea of IPDI and DETA, as well as microcapsules.

The FTIR spectra of photochromic solution, polyurea, and microcapsules are shown in Figure 2. In the spectrum of the photochromic solution, the bands at $2875 \mathrm{~cm}^{-1}$ and $2972 \mathrm{~cm}^{-1}$ could belong to the symmetric and asymmetric stretching vibration of $-\mathrm{CH}_{3}$, respectively. The peaks of $1375 \mathrm{~cm}^{-1}$ and $1452 \mathrm{~cm}^{-1}$ may be attributed to the symmetric and asymmetric formation vibration of $-\mathrm{CH}_{3}$ respectively, which also illustrate the existence of $-\mathrm{CH}_{3}$. The peak at $2933 \mathrm{~cm}^{-1}$ is the stretching vibration of $-\mathrm{CH}_{2}$. The benzene ring is certified to exist by a series of peaks at $1604,1500 \mathrm{~cm}^{-1}$, which belong to the vibration of benzene ring carbon backbone, and $825,756,700 \mathrm{~cm}^{-1}$, which are attributed to the bending vibration of $-\mathrm{CH}$ on benzene. In the spectrum of polyurea, a strong stretching vibration of $-\mathrm{C}=\mathrm{O}$ appears at the peak of $1643 \mathrm{~cm}^{-1}$; The bending vibration of the $-\mathrm{NH}$ peak is observed at $1560 \mathrm{~cm}^{-1}$, and a broad peak around $3350-3200 \mathrm{~cm}^{-1}$ is the stretching vibration of $-\mathrm{NH}$. Besides, there does not exist the peak around $2260 \mathrm{~cm}^{-1}$, which is to indicate the existence of $-\mathrm{NCO}$, so it demonstrates that the IPDI monomers had fully reacted. All peaks on the aforementioned spectra appear on the spectrum of the microcapsule and there are no other new peaks appearing; therefore, we can conclude that the microcapsule is composed of the photochromic solution and polyurea, and the monomers do not react with the photochromic solution.

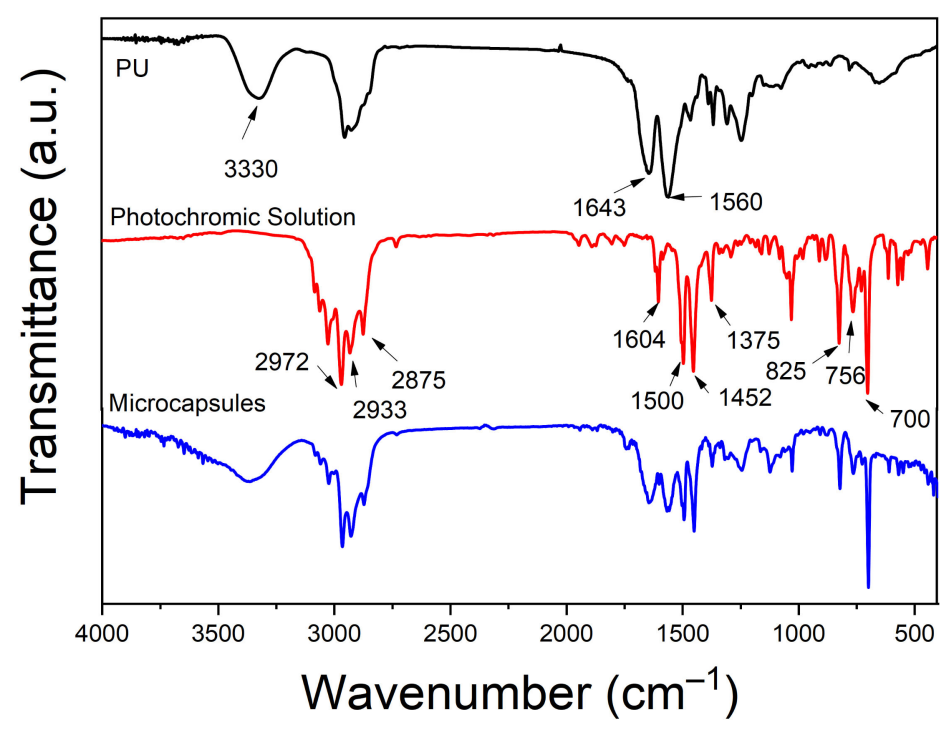

Figure 2. The infrared spectrum of NP solution, PU, and microcapsules.

\subsection{Particle Size and Its Distribution}

The particle size and distribution of microcapsules are affected by many factors in the preparation. Among them, the initial addition amount of raw materials, emulsifier, and stirring rate of emulsification are worth noting.

The particle size of microcapsules prepared with different amounts of oil phase solution was measured. The result was shown in Figure 3. From Figure 3, it can be seen that the microcapsules have relatively narrow size distributions with average diameters of 0.58 and $0.74 \mu \mathrm{m}$ when the percentage of the oil phase in the emulsion is $6 \%$ and $9 \%$, respectively. With the addition amount increasing, the size distribution becomes broader. When the percentage of the oil phase is larger than $15 \%$, two peaks appear on the curve of the size distribution of microcapsules and the average diameters become larger. This may be due to a high concentration of dispersed phase. As the concentration of the dispersed phase in the emulsion increases, the probability of collisions between dispersed phase particles increases, so the coalescence becomes easier for the emulsion. Moreover, the 
reaction rate becomes larger because the concentration of IPDI increases with the dispersed phase, which leads to the agglomeration of microcapsules. Therefore, for the purpose of obtaining uniform microcapsules, it is better to add raw materials of not more than $15 \%$ in weight.

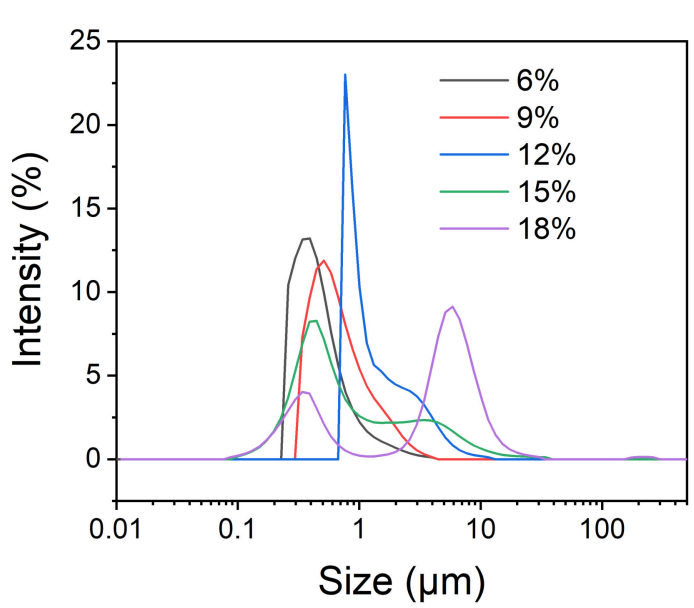

(a)

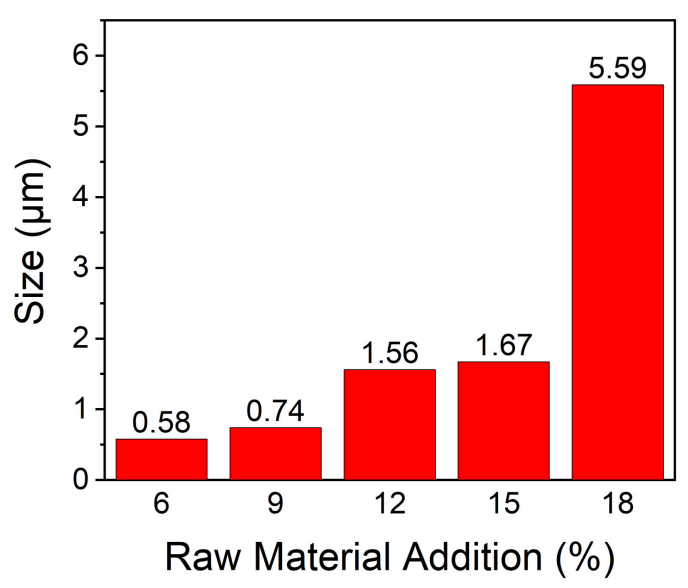

(b)

Figure 3. The size and size distribution of microcapsules prepared with different addition amount of oil phase (a) and the average diameters $(\mathbf{b})$.

Emulsifier plays an important role in decreasing the interfacial tension and minimizing the effects of interfacial forces in emulsions. Figure 4 shows the influence of emulsifier addition on the particle size and particle size distribution. It can be seen that the particle size distributions become narrow and the average diameters decrease with the increasing addition of the emulsifier. The microcapsules' average diameter reduces to $0.83 \mu \mathrm{m}$ from $1.52 \mu \mathrm{m}$ as the addition amount of emulsifier increases to $0.4 \%$ from $0.2 \%$. With a further increase dosage of emulsifier, the particle size decreases slightly. As we know, the emulsion forms relying on the emulsifier surrounding the surface of dispersed droplets. The smaller the droplets are, the larger the area of the interface formed in the emulsion, and the more emulsifier the molecules need. There are not enough emulsifier molecules to form a stable layer around the emulsion droplets when the emulsifier addition is $0.2 \%$, so the droplets tend to agglomerate to form larger droplets. When the percentage of emulsifier exceeds $0.4 \%$, the emulsifier is not the main factor to affect the formation of emulsion anymore, therefore the microcapsules' size does not decrease that obviously with more emulsifier added. As a consequence, microcapsules with relatively small diameter and narrow particle distribution were prepared with an emulsifier addition of $0.4 \%$.

The shearing force of core material is obtained through mechanical stirring. Different stirring rates provide different shearing forces for the emulsion, hence, the stirring rate affects the formation of the emulsion. As shown in Figure 5, the size of the microcapsules becomes small and the particle size distribution becomes narrow gradually as the stirring rate becomes large. The average diameter of the microcapsules decreases from $0.92 \mu \mathrm{m}$ to $0.56 \mu \mathrm{m}$ when the stirring rate increase from $1200 \mathrm{r} / \mathrm{min}$ to $2000 \mathrm{r} / \mathrm{min}$. This may be explained as follows: emulsions are not thermodynamically stable, and the dispersed droplets will agglomerate and adhere together when without external force. Mechanical stirring can put a shearing force to the oil phase and there is a positive correlation between shearing force with the stirring rate. When the stirring rate increases, the shearing force becomes large, which leads to the droplets keeping a balance of dispersing and agglomeration in a smaller size. However, the diameters of microcapsules prepared at the stirring rate of $1800 \mathrm{r} / \mathrm{min}$ and $2000 \mathrm{r} / \mathrm{min}$ are not much of a distinction, so the stirring rate of $1800 \mathrm{r} / \mathrm{min}$ is good enough for the emulsion system. 


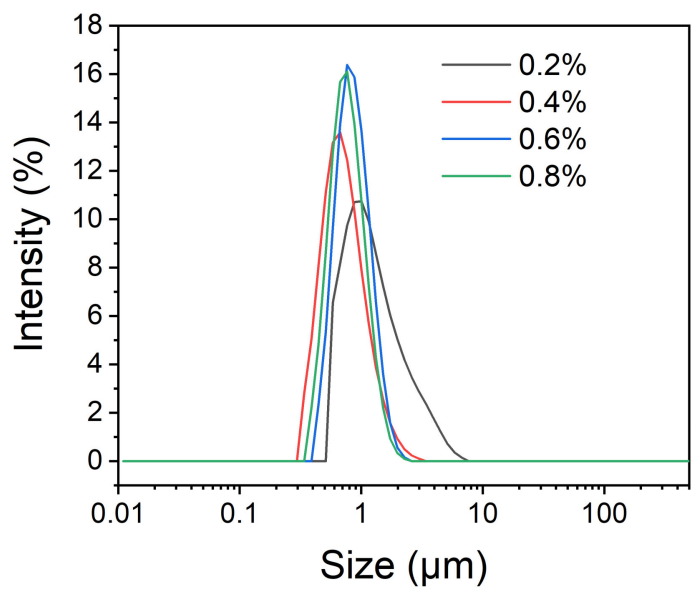

(a)

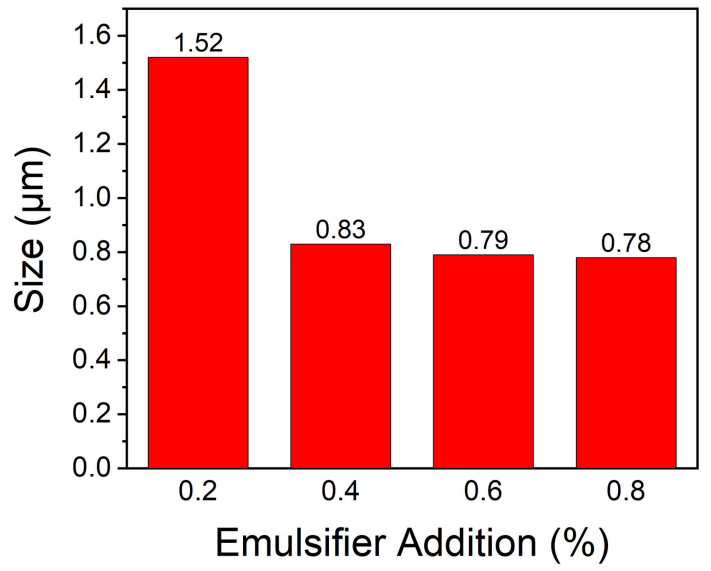

(b)

Figure 4. The size and size distribution of microcapsules prepared with different addition amount of emulsifier (a) and the average diameters $(\mathbf{b})$.

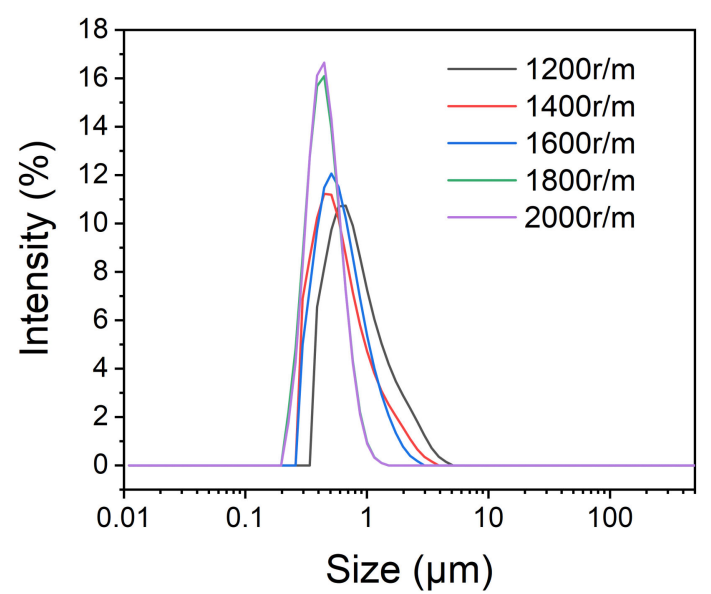

(a)

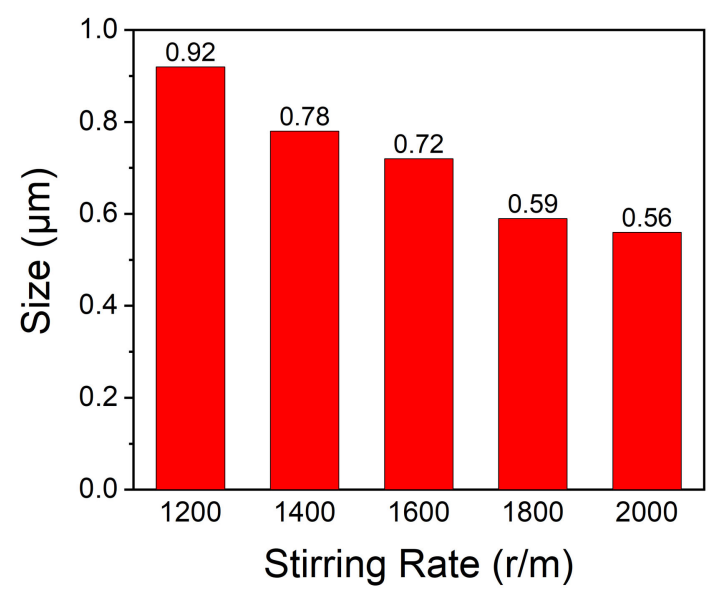

(b)

Figure 5. The size and size distribution of microcapsules prepared under different stirring rates (a) and the average diameters (b).

\subsection{Morphology of the Microcapsules}

The morphology of the microcapsules prepared with different ratios of core material and shell material was evaluated via SEM. The SEM images of microcapsules are shown in Figure 6. It can be seen that all the microcapsules are almost spherical. The diameters observed on the SEM images range from 0.2 to $0.4 \mu \mathrm{m}$, which is slightly smaller than that measured by the laser particle size analyzer. There may be two reasons for this. On one hand, we obtained the particle size using the laser particle size analyzer by recording the Brownian motion of particles in the dispersion, so there is a certain deviation from the value obtained by SEM. On the other hand, the microcapsules agglomerate together easily, it is hard to obtain the suspension with single microcapsules dispersed. Therefore, the diameters we measured via the laser particle size analyzer were actually the agglomerated microcapsules. 


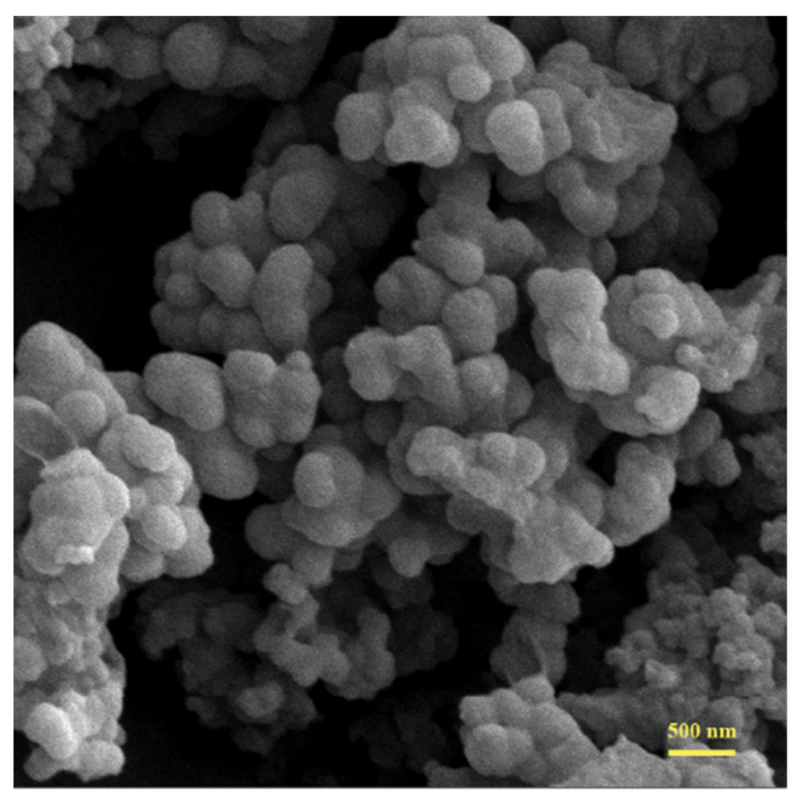

(a)

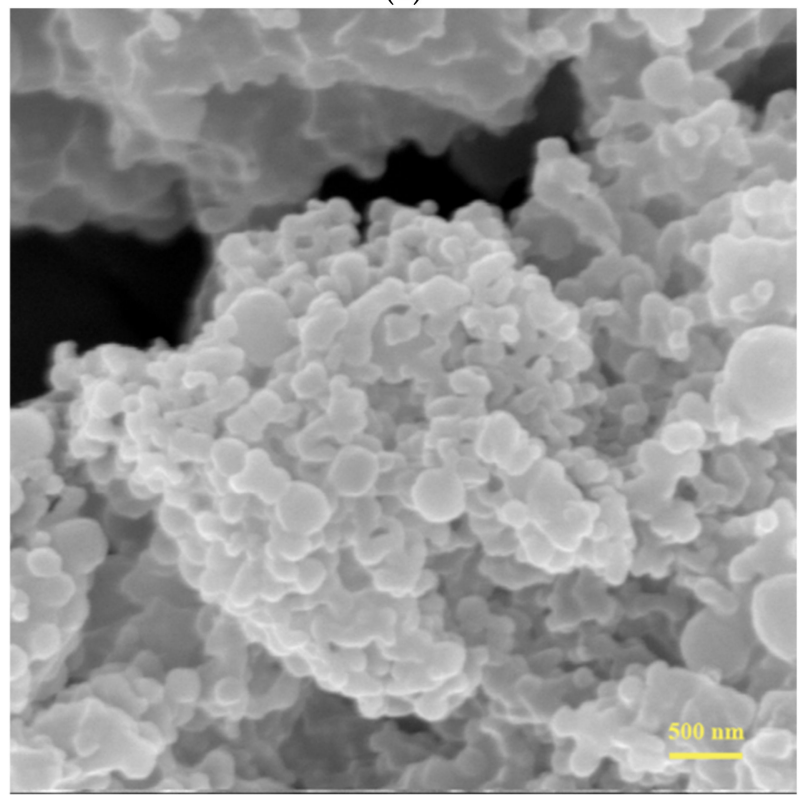

(c)

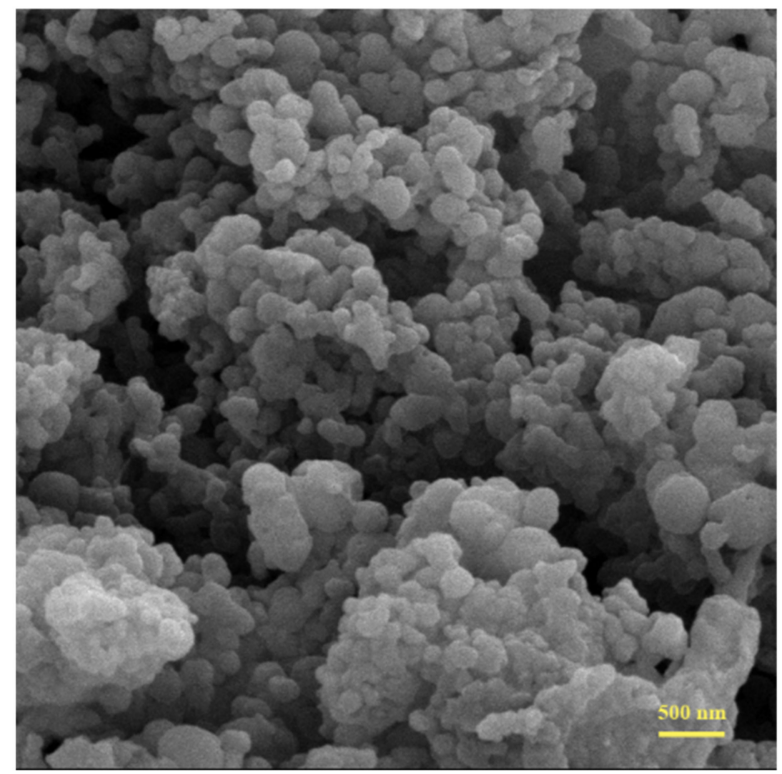

(b)

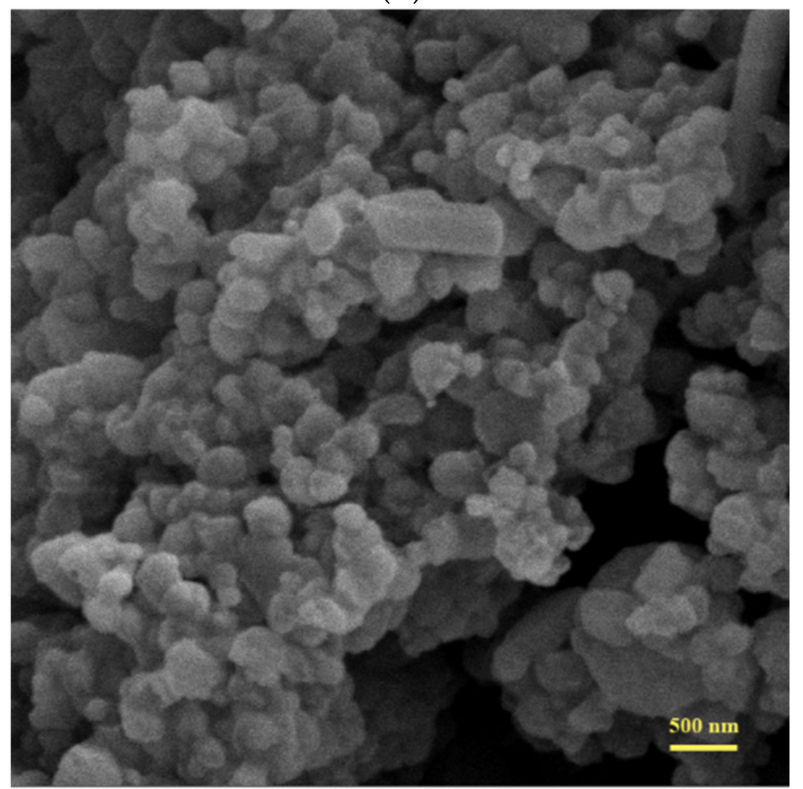

(d)

Figure 6. SEM of the microcapsules prepared by different core/shell ratio: (a) 1:1 (b) 2:1 (c) 3:1 (d) 4:1.

From Figure 6, we can see that the microcapsules could be formed with different dosages of shell material. However, there are obvious differences in shape and morphology of the microcapsules of different core/shell ratios. From Figure $6 c$,d, it can be seen that the microcapsules synthesized with core/shell ratios of 4:1 and 3:1 cluster more seriously compared with those synthesized with core/shell ratios of 2:1 and 1:1. Moreover, there appear crystals when the core/shell ratio is 4:1, which illustrates that the encapsulation performance of the microcapsules is too poor so the core materials will seep out gradually. From Figure $6 a, b$, we can observe that the microcapsules are more uniform and the surfaces are more smooth when the core/shell ratio is 1:1. In summary, better microcapsules were obtained with the increased amount of shell material, so in order to guarantee the encapsulation property of the microcapsules, we should appropriately increase the shell material when preparing the microcapsules. In this work, the core/shell ratio of 1:1 is relatively suitable for the formation of the microcapsules. 


\subsection{Thermogravimetric Analysis (TGA)}

To investigate the thermostability of the microcapsules and to calculate the core content encapsulated in the microcapsules, TGA curves of the microcapsules prepared with different ratios of core material and shell material were obtained via a thermogravimetric analyzer. As discussed in the analysis of SEM, the microcapsules are not that reliable when the core/shell ratio is 4:1, so we ignore the thermogravimetric analysis of them prepared with the core/shell ratio of $4: 1$. Figure 7 is the TGA results of shell material, photochromic solution, and microcapsules prepared with different core/shell ratios, and the details of the decomposition temperatures and char yield of the samples are shown in Table 1. According to the TGA curves, the photochromic solution began to lose weight at $149{ }^{\circ} \mathrm{C}\left(\mathrm{T}_{10 \%}\right)$, which was mainly caused by the evaporation of the solvent. The shell material of polyurea (PU) synthesize by IPDI and DETA is quite stable to temperature. The PU shell without core solution started to break down until the temperature rises to $317^{\circ} \mathrm{C}$ and decomposed completely at about $465^{\circ} \mathrm{C}$, which led to a sharp drop of the TGA curve of PU at $317-465^{\circ} \mathrm{C}$ [33]. Considering the microcapsules fabricated with core/shell ratios of 1:1, 2:1, and 3:1, there were two stages of weight loss in the process of temperature rise on all TGA curves of microcapsules. The first began at about 169 to $178^{\circ} \mathrm{C}$ and the second began at about $317^{\circ} \mathrm{C}$; they were attributed to the evaporation of the core solution and the decomposition of the shell, respectively. The temperature at which photochromic solution in microcapsules starts to lose weight is higher than that without encapsulation. This proves that the microcapsules can protect the photochromic solution from evaporation to a certain degree. The decomposition temperature of the microcapsules' shell is in correspondence with that of PU synthesized by IPDI and DETA, which illustrates the shell material keeps its performance when used in microcapsules. It is worth noting that there exists an obvious difference on the TGA curves of microcapsules with core/shell ratios of 1:1 compared to that of 2:1 and 3:1. Both the microcapsules with core/shell ratios of 2:1 and 3:1 lost weight rapidly at the temperature from 169 to $240{ }^{\circ} \mathrm{C}$ and then had a platform until the shell material started to break down, However, when the microcapsules' core/shell ratio was $1: 1$, the TGA curve dropped nearly linearly with a slow rate at the temperature from 178 to $308^{\circ} \mathrm{C}$. Microcapsules could prevent the formed vapor from volatilizing because the thick shell formed when the core/shell ratio was 1:1. When the core/shell ratios were 2:1 and $3: 1$, the shell of the formed microcapsules might be too thin to keep the core solution from permeating out at a relatively high temperature. Therefore, to make the microcapsules better in encapsulation performance, increasing the shell material amount is necessary.

Table 1. Results of the thermogravimetric analysis of PU, NP solution, and microcapsules with core/shell ratio of 1:1, 2:1 and 3:1.

\begin{tabular}{ccc}
\hline Samples & $\mathbf{T}_{\mathbf{1 0} \%}\left({ }^{\circ} \mathbf{C}\right)$ & Char Yield (\%) \\
\hline NP Solution & 149 & 0.04 \\
PU & 317 & 3.10 \\
Core/shell ratio of $1: 1$ & 178 & 2.69 \\
Core/shell ratio of 2:1 & 171 & 1.12 \\
Core/shell ratio of 3:1 & 169 & 0.79 \\
\hline
\end{tabular}

Note: The decomposition temperatures of the samples we used were the temperatures at which the samples' thermal weight losses were $10 \%$, marked as $\mathrm{T}_{10 \%}$. 


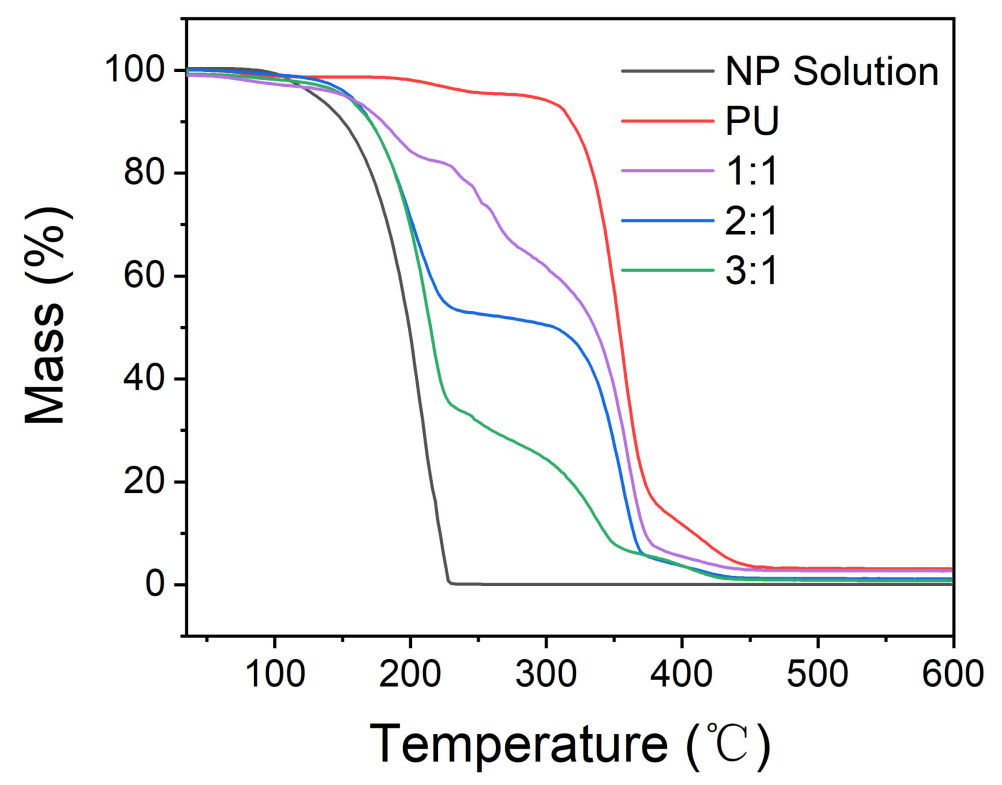

Figure 7. TGA curves of PU, NP solution, and microcapsules with core/shell ratio of 1:1, 2:1, and 3:1.

To further confirm the microcapsules' stability of encapsulation, the samples were heated to $80^{\circ} \mathrm{C}$ in an oven, and the masses were recorded every $4 \mathrm{~h}$. The result was shown in Figure 8. We can conclude that with the increase of core/shell ratio, the tightness of the microcapsules becomes worse, so the mess loss increased. This is consistent with the result of the TGA analysis.

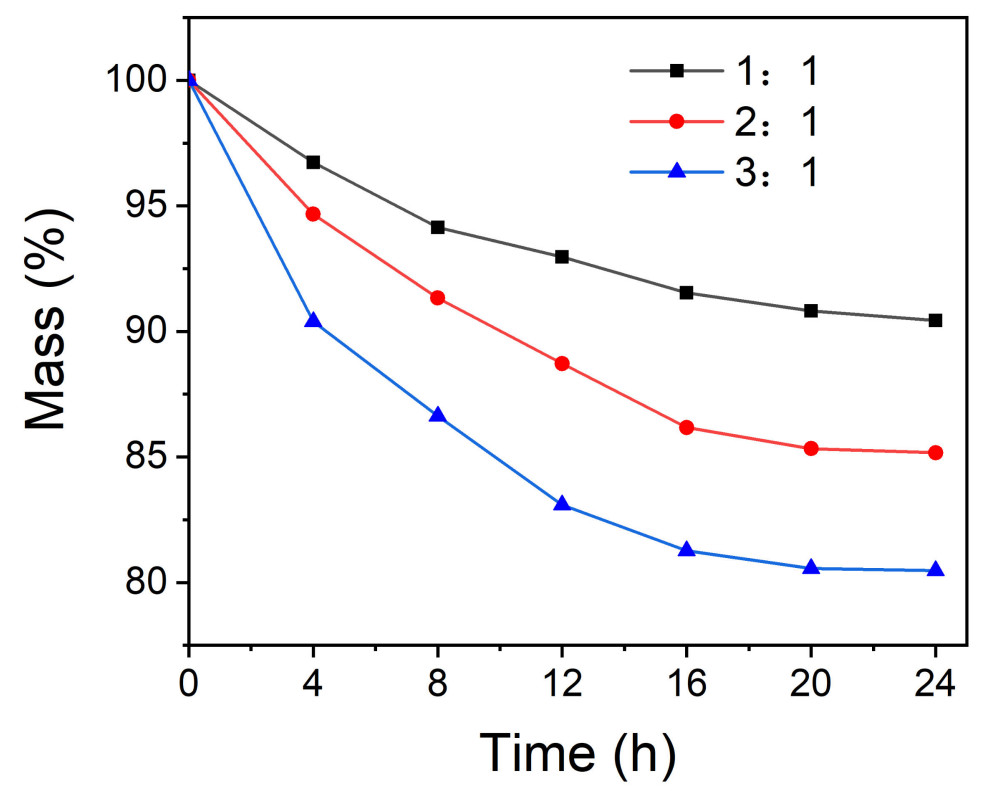

Figure 8. The mass loss of the microcapsules with core/shell ratio of $1: 1,2: 1$ and $3: 1$ at $80{ }^{\circ} \mathrm{C}$.

\subsection{Photochromic Performance}

As seen in Figure 9, reversible structural transformation occurs in 3,3-Diphenyl$3 \mathrm{H}-$ naphtho[2,1-b] pyran (NP) under UV and visible light [39]. The colorless form (CF) undergoes a ring-opening reaction to form two kinds of colored forms of cis (TC) and trans (TT) structures under the UV light. On the contrary, the colored forms revert to the original structure when the UV light is removed. The responding time of the microcapsules' colorchanging was tested by recording the chromatic aberration $(\Delta \mathrm{E})$. The result was shown in Figure 10. We can see that the chromatic aberration of the microcapsules reached the 
maximum value after $6 \mathrm{~s}$ UV light irradiation. After that, when we continued to extend the time of UV light irradiation to the samples, the chromatic aberration was almost unchanged, which illustrated the reaction reaches a state of dynamic equilibrium. When the UV light was removed, the chromatic aberration decreased gradually and it took about $90 \mathrm{~s}$ to restore to the original color, which meant the colored form of the TF and TT structures reverted to the colorless form of CF.

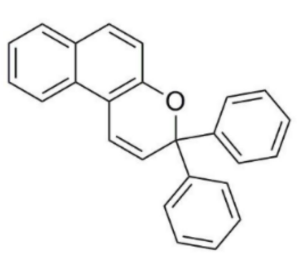

CF

Colorless Closed form

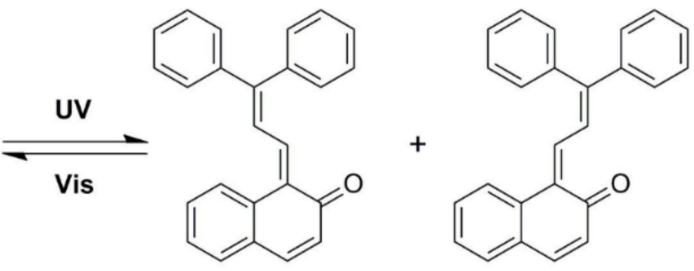

TT
Colored

Open form

Figure 9. Reversible structural transformation of 3,3-diphenyl-3H-naphtho[2,1-b] pyran (NP) under UV and visible light.

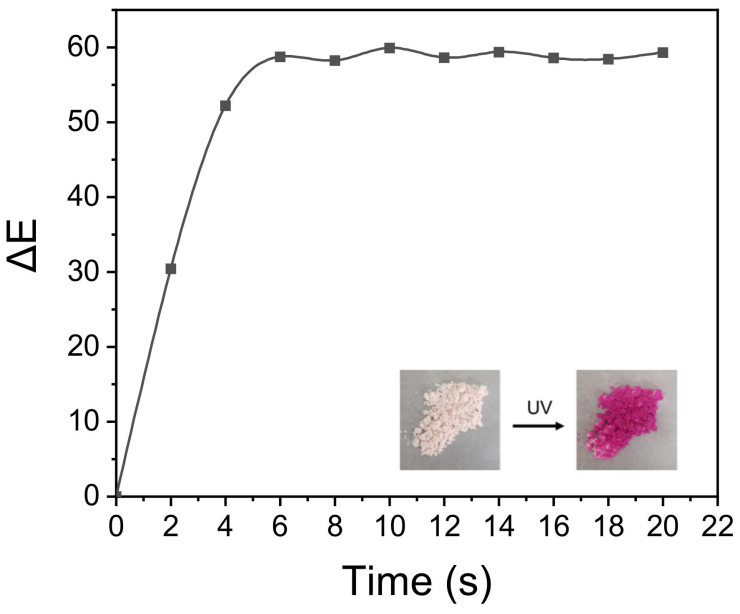

(a)

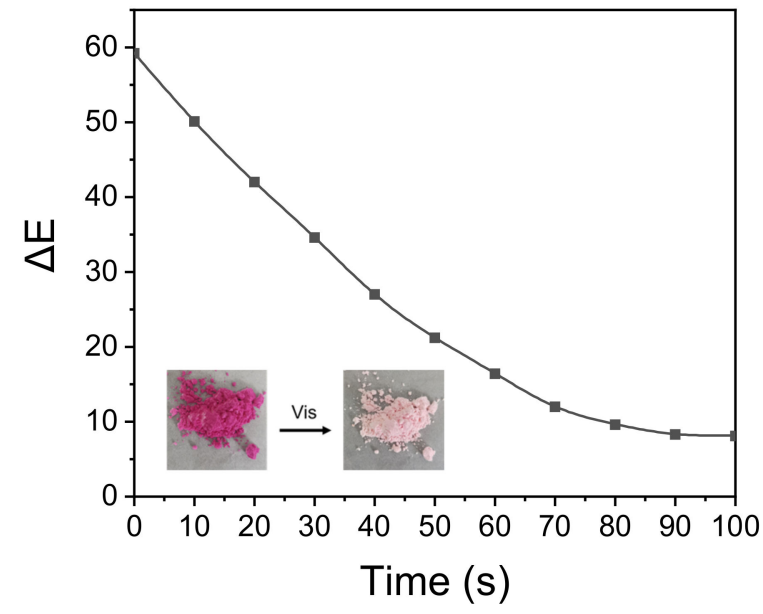

(b)

Figure 10. The chromatic aberration $(\Delta \mathrm{E})$ of the microcapsules under UV irradiation (a) and the fading time under visible light (b).

As we know, polymers break down easily under the irradiation of UV light. It is meaningful to add the photostabilizer to the polymers to reduce the impact of the UV light $[40,41]$. In the photochromic microcapsules in particular, UV light is necessary to obtain color-changing. In order to extend the service life of the microcapsules, we applied the bis(2,2,6,6-tetramethyl-4-piperidinyl)sebacate (HALS 770) as the photostabilizer to the microcapsules.

For the purpose of investigating the effect of photostabilizer on the color-changing of the photochromic microcapsules, samples with different amounts of HALS 770 were obtained. We tested the absorbance of the microcapsules suspension at $550 \mathrm{~nm}$ after UV light irradiation. Figure 11 showed the result of 100 color-changing cycles. We can see that the absorbances of the microcapsules with different amounts of HALS 770 were nearly constant, which meant the addition of the photostabilizer had little impact on the absorbance of the microcapsules. Both the microcapsules with and without photostabilizer have excellent fatigue resistance. Table 2 showed the chromatic aberration of microcapsules with different amounts of HALS 770 before and after UV light irradiation after 100 color- 
changing cycles. The results illustrate that all the samples kept a good color-changing property, and the chromatic aberration values remained above 30 , which meant there was a significant color change before and after UV light irradiation to the microcapsules.

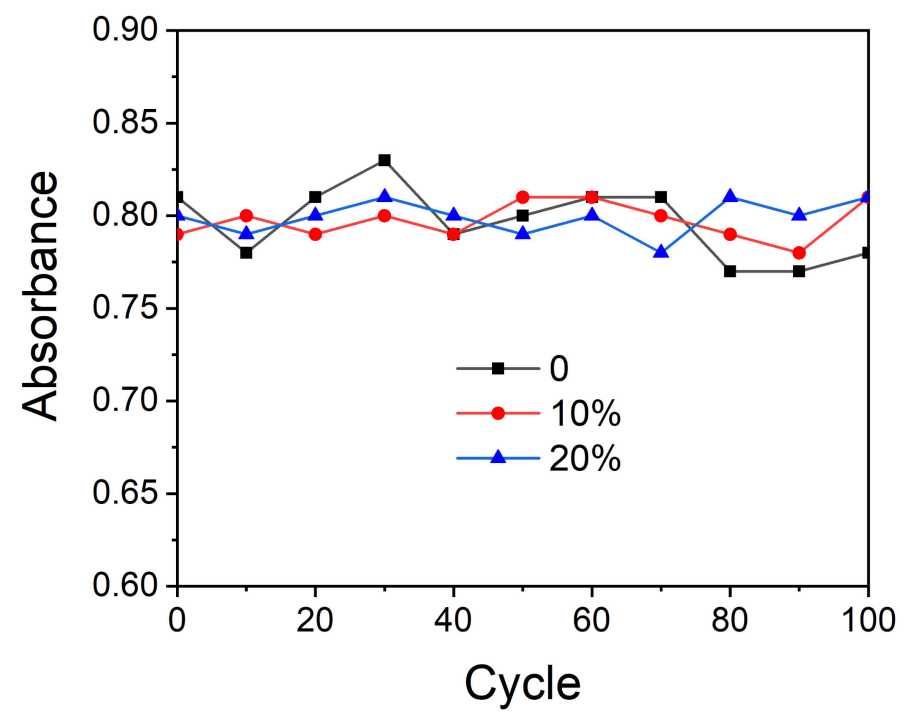

Figure 11. The effect of HALS 770 on the absorbance of the microcapsules.

Table 2. The color parameter of microcapsules with different content of HALS 770.

\begin{tabular}{ccccc}
\hline & & \multicolumn{3}{c}{ Content of HALS 770 (\%) } \\
\cline { 3 - 5 } & & $\mathbf{0}$ & $\mathbf{1 0}$ & $\mathbf{2 0}$ \\
\hline \multirow{2}{*}{ Before UV light } & $\mathrm{L}$ & 84 & 84 & 82 \\
irradiation & $\mathrm{a}$ & 6 & 7 & 7 \\
\hline \multirow{2}{*}{ After UV light } & $\mathrm{b}$ & 6 & 6 & 6 \\
irradiation & $\mathrm{L}$ & 33 & 31 & 73 \\
\hline$\Delta \mathrm{E}$ & $\mathrm{a}$ & -12 & -9 & 34 \\
\hline & $\mathrm{b}$ & 36.63 & 31.92 & -16 \\
\hline
\end{tabular}

To further corroborate the effect of the photostabilizer on the photochromic microcapsules, a UV accelerated aging test was carried out. The absorbances of the microcapsules with $0,10 \%$ and $20 \%$ (compared to the amount of NP) addition of HALS 770 were shown in Figure 12. According to Figure 12a, when the addition of the photostabilizer was 0, the absorbance of the microcapsules at $550 \mathrm{~nm}$ decreased rapidly as the $\mathrm{UV}$ accelerated aging test time increased, and the absorbance at $550 \mathrm{~nm}$ was less than a half after $15 \mathrm{~d}$. From Figure 12b, when the addition amount of the photostabilizer was 10\%, the absorbance of the microcapsules at $550 \mathrm{~nm}$ decreased slightly in the first $6 \mathrm{~d}$, and then it remained nearly unchanged in the following UV accelerated aging test. As shown in Figure 12c, when the addition amount of HALS 770 increased to $20 \%$, the absorbance of the microcapsules hardly declined at the UV accelerated aging test. We can conclude that the addition of HALS 770 can protect the microcapsules from the damage of the UV light so it can extend the service life of the microcapsules. The mechanism for the stabilization of microcapsules may be explained as follows [42]: free alkoxyl radicals and free alkyl radicals are formed when the microcapsules are exposed to UV light. HALS 770 possesses alicyclic amines that can be transformed into regenerating free nitroxyl radicals. The free nitroxyl can catch free alkoxyl and alkyl radicals formed during the aging of the microcapsules to form the appropriate esters. The esters formed can react with free radicals to regenerate free nitroxyl radicals and build organic molecular chains, so a large number of free radicals is consumed, resulting in the delay of the aging process. When the addition of HALS 770 was $10 \%$, the 
concentration of HALS 770 might not be high enough to consume the free radicals formed during the aging test, so the microcapsules decompose partially, leading to the decrease of the absorbance of the microcapsules at $550 \mathrm{~nm}$. When the addition of HALS 770 reached $20 \%$, the free radicals could be consumed relatively completely, so the microcapsules had a good performance in the aging test.

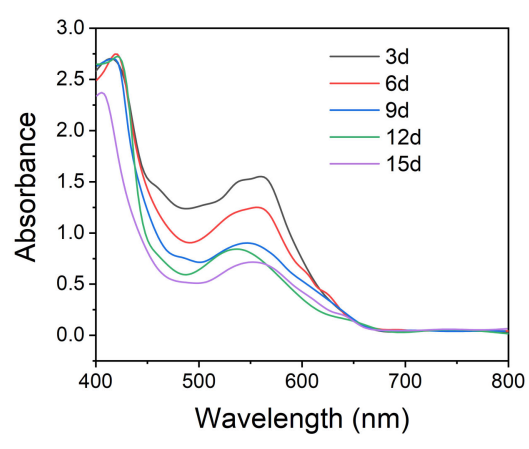

(a)

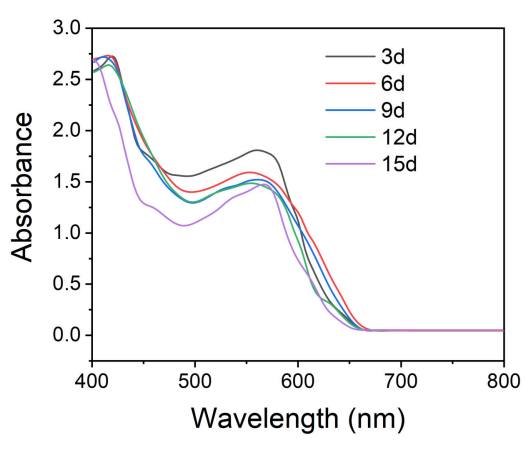

(b)

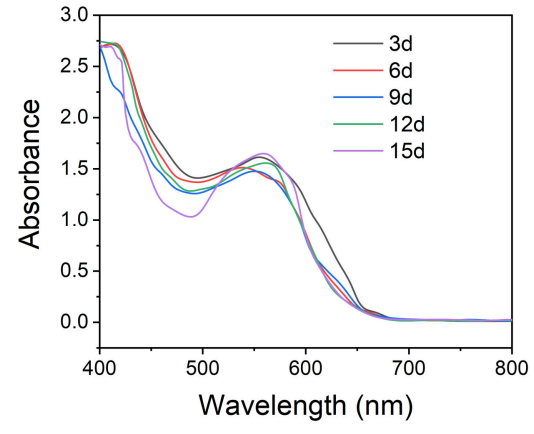

(c)

Figure 12. The absorbance of the microcapsules with different content of HALS 770 during the UV accelerated aging test. The content of HALS 770 in the microcapsules: (a) 0; (b) 10\%; (c) $20 \%$.

\section{Conclusions}

In this work, photochromic microcapsules had been prepared via interfacial polymerization. Polyurea synthesized by IPDI and DETA was suitable for the shell material in the microcapsules. The FTIR spectra demonstrated that the microcapsules consisted of the photochromic solution and polyurea. The percentage of the oil phase in the emulsion, addition of emulsifier and stirring rate had a great effect on the particle size and particle size distribution. When the percentage of the oil phase was less than $15 \%$ and the dosage of the emulsifier was $0.4 \%$ and the stirring rate was $1800 \mathrm{r} / \mathrm{min}$, the microcapsules had a relatively uniform particle size of about $0.56 \mu \mathrm{m}$. The core/shell ratio impacted the micromorphology and the stability of the microcapsules. When the core/shell ratio was 1:1, the microcapsules had good performance in thermal stability. After encapsulation, the thermal weight loss temperature increased from 149 to $178^{\circ} \mathrm{C}$. The microcapsules had a very fast response rate to the UV light, and it took only $6 \mathrm{~s}$ to reach the max chromatic aberration value for the microcapsules under the UV light irradiation. HALS 770 as the photostabilizer had little impact on the color-changing property. The microcapsules with and without HALS 770 showed an excellent performance on the color-changing cycle property. However, HALS 770 could affect the UV aging resistance of the microcapsules. When adding $20 \%$ HALS 770, the absorbance of microcapsules kept nearly consistent during the UV accelerated aging test, which meant HALS 770 could protect the microcapsule from the UV light damage. This research provides new insight into the application of photochromic materials, and there are some other issues worthy of further study in the follow-up work, such as the thickness of the microcapsules' shell, the method to reduce agglomeration of microcapsules, and the influence of solvent on the microcapsules' photochromic property, etc.

Author Contributions: Conceptualization, Z.C. and Y.Z.; methodology, Y.Z. and Y.Y.; software, Y.Z. and X.Z.; validation, Y.Z. and X.Z.; formal analysis, Y.Z.; investigation, Y.Z. and X.Z.; resources, Z.C.; data curation, Y.Z.; writing-original draft preparation, Y.Z.; writing—review and editing, Z.C. and Y.Y.; visu-alization, Y.Z. and X.Z.; supervision, Z.C.; project administration, Z.C.; funding acquisition, Z.C. All authors have read and agreed to the published version of the manuscript.

Funding: This research was funded by the National Natural Science Foundation of China (21676096 and 20775088).

Institutional Review Board Statement: Not applicable. 
Informed Consent Statement: Not applicable.

Data Availability Statement: The data presented in this study are available on request from the corresponding author.

Conflicts of Interest: The authors declare no conflict of interest.

\section{References}

1. Wang, M.S.; Xu, G.; Zhang, Z.J.; Guo, G.C. Inorganic-organic hybrid photochromic materials. Chem. Commun. 2010, 46, 361-376. [CrossRef]

2. Gao, Y.; Yao, W.; Sun, J.; Li, K.; Zhang, L. Angular photochromic LC composite film for an anti-counterfeiting label. Polymers 2018, 10, 453. [CrossRef] [PubMed]

3. Wang, S.; Fan, W.; Liu, Z.; Yu, A.; Jiang, X. Advances on tungsten oxide based photochromic materials: Strategies to improve their photochromic properties. J. Mater. Chem. C 2018, 6, 191-212. [CrossRef]

4. Cheng, T.; Lin, T.; Brady, R.; Wang, X. Fast response photochromic textiles from hybrid silica surface coating. Fibers Polym. 2008, 9 , 301-306. [CrossRef]

5. Ma, L.; Li, C.; Yan, Q.; Wang, S.; Miao, W.; Cao, D. Unsymmetrical photochromic bithienylethene-bridge tetraphenylethene molecular switches: Synthesis, aggregation-induced emission and information storage. Chin. Chem. Lett. 2020, 31, 361-364. [CrossRef]

6. Torres-Pierna, H.; Ruiz-Molina, D.; Roscini, C. Highly transparent photochromic films with a tunable and fast solution-like response. Mater. Horiz. 2020, 7, 2749-2759. [CrossRef]

7. Tsujioka, T.; Nakanishi, Y.; Nishimura, R.; Uchida, K. Measurement of glass-transition temperature of thermoreversible photochromic materials based on mechanochemical amorphization. Dye. Pigment. 2021, 186, 109069. [CrossRef]

8. Abdelghany, A.M. Photochromic behavior of tungsten ions in sodium metaphosphate glass and effect of oxidizing condition assessed by spectroscopic analysis. J. Non-Cryst. Solids 2021, 552, 120460. [CrossRef]

9. Vyasamudri, S.; Yang, D. Regiodivergent synthesis of Bis(4-oxycoumarin)-based dioxabicycles: Exploration of [4 + 4] (heterocyclo)reversion/addition and 1,5-hydrogen shift photochromism. Org. Lett. 2020, 22, 3166-3170. [CrossRef]

10. Helmy, S.; Leibfarth, F.A.; Oh, S.; Poelma, J.E.; Hawker, C.J.; de Alaniz, J.R. Photoswitching using visible light: A new class of organic photochromic molecules. J. Am. Chem. Soc. 2014, 136, 8169-8172. [CrossRef]

11. Ge, B.; Han, S.; Wei, Q.; Li, J.; Wang, G. Coordination-driven strategy towards crystalline hybrid photochromic materialsvia the marriage of a non-photochromic extended dipyridine unit and zincophosphate. J. Mater. Chem. C 2019, 7, 3920-3923. [CrossRef]

12. Fu, Z.; Sun, B.; Chen, J.; Yuan, L. Preparation and photochromism of carboxymethyl chitin derivatives containing spirooxazine moiety. Dye. Pigment. 2008, 76, 515-518. [CrossRef]

13. Zhao, X.; Wang, G.; Zhang, K. Photochromic behavior of naphthopyran in styrene-butadiene-styrene elastomer thin films: Effect of stretching of film and linker. J. Appl. Polym. Sci. 2013, 127, 1794-1802. [CrossRef]

14. Dridi, H.; Boulmier, A.; Bolle, P.; Dolbecq, A.; Rebilly, J.; Banse, F.; Ruhlmann, L.; Serier-Brault, H.; Dessapt, R.; Mialane, P.; et al. Directing the solid-state photochromic and luminescent behaviors of spiromolecules with Dawson and Anderson polyoxometalate units. J. Mater. Chem. C 2020, 8, 637-649. [CrossRef]

15. Fan, J.; Bao, B.; Wang, Z.; Xu, R.; Wang, W.; Yu, D. High tri-stimulus response photochromic cotton fabrics based on spiropyran dye by thiol-ene click chemistry. Cellulose 2020, 27, 493-510. [CrossRef]

16. Huo, Z.; Li, G.; Xiao, X. Applications of organic photochromic materials in rapid visual detection. Prog. Chem. 2017, 29, 252-261.

17. He, Z.; Wang, W.; Fan, J.; Bao, B.; Qin, X.; Yu, D. Photochromic microcapsules anchored on cotton fabric by layer-by-layer self-assembly method with erasable property. React. Funct. Polym. 2020, 157, 104762. [CrossRef]

18. Irie, M.; Sayo, K. Solvent effects on the photochromic reactions of diarylethene derivatives. J. Phys. Chem. B 1992, 96, 7671-7674. [CrossRef]

19. Mallo, N.; Brown, P.T.; Iranmanesh, H.; MacDonald, T.S.C.; Teusner, M.J.; Harper, J.B.; Ball, G.E.; Beves, J.E. Photochromic switching behaviour of donor-acceptor Stenhouse adducts in organic solvents. Chem. Commun. 2016, 52, 13576-13579. [CrossRef] [PubMed]

20. Patel, K.; Castillo-Muzquiz, A.; Biewer, M.C. Studying monolayer/solvent interactions with a photochromic compound in a self-assembled monolayer. Tetrahedron Lett. 2002, 43, 5933-5935. [CrossRef]

21. Brown, E.N.; White, S.R.; Sottos, N.R. Microcapsule induced toughening in a self-healing polymer composite. J. Mater. Sci. 2004, 39, 1703-1710. [CrossRef]

22. Chu, L.Y.; Yamaguchi, T.; Nakao, S. A molecular-recognition microcapsule for environmental stimuli-responsive controlled release. Adv. Mater. 2002, 14, 386-389. [CrossRef]

23. Wang, Y.; Lu, Z.; Wu, H.; Lv, F. Study on the antibiotic activity of microcapsule curcumin against foodborne pathogens. Int. J. Food Microbiol. 2009, 136, 71-74. [CrossRef]

24. Zhao, Y.; Zhang, W.; Liao, L.P.; Wang, S.J.; Li, W.J. Self-healing coatings containing microcapsule. Appl. Surf. Sci. 2012, 258, 1915-1918. [CrossRef]

25. Xu, C.; Zeng, X.; Yang, Z.; Ji, H. Sunscreen enhancement of octyl methoxycinnamate microcapsules by using two biopolymers as wall materials. Polymers 2021, 13, 866. [CrossRef] [PubMed] 
26. Bayés-García, L.; Ventolà, L.; Cordobilla, R.; Benages, R.; Calvet, T.; Cuevas-Diarte, M.A. Phase change materials (PCM) microcapsules with different shell compositions: Preparation, characterization and thermal stability. Sol. Energy Mater. Sol. Cells 2010, 94, 1235-1240. [CrossRef]

27. Jia, J.; Wang, C.; Chen, K.; Yin, Y. Drug release of yolk/shell microcapsule controlled by pH-responsive yolk swelling. Chem. Eng. J. 2017, 327, 953-961. [CrossRef]

28. Cam, M.E.; Zhang, Y.; Edirisinghe, M. Electrosprayed microparticles: A novel drug delivery method. Expert Opin. Drug Deliv. 2019, 16, 895-901. [CrossRef]

29. Feczkó, T.; Varga, O.; Kovács, M.; Vidóczy, T.; Voncina, B. Preparation and characterization of photochromic poly (methyl methacrylate) and ethyl cellulose nanocapsules containing a spirooxazine dye. J. Photochem. Photobiol. A Chem. 2011, 222, 293-298. [CrossRef]

30. Zhou, Y.; Yan, Y.; Du, Y.; Chen, J.; Hou, X.; Meng, J. Preparation and application of melamine-formaldehyde photochromic microcapsules. Sens. Actuators B Chem. 2013, 188, 502-512. [CrossRef]

31. Di Credico, B.; Griffini, G.; Levi, M.; Turri, S. Microencapsulation of a UV-responsive photochromic dye by means of novel UV-screening polyurea-based shells for smart coating applications. ACS Appl. Mater. Interfaces 2013, 5, 6628-6634. [CrossRef]

32. Tsuru, Y.; Kohri, M.; Taniguchi, T.; Kishikawa, K.; Karatsu, T.; Hayashi, M. Preparation of photochromic liquid core nanocapsules based on theoretical design. J. Colloid Interface Sci. 2019, 547, 318-329. [CrossRef]

33. Scher, H.B.; Rodson, M.; Lee, K.S. Microencapsulation of pesticides by interfacial polymerization utilizing isocyanate or aminoplast chemistry. Pestic. Sci. 1998, 54, 394-400. [CrossRef]

34. Sun, S.; Gao, Y.; Han, N.; Zhang, X.; Li, W. Reversible photochromic energy storage polyurea microcapsules via in-situ polymerization. Energy 2021, 219, 119630. [CrossRef]

35. Kulkarni, A.; Dasari, H. Current Status of Methods Used in Degradation of Polymers: A Review. In Proceedings of the MATEC Web of Conferences, Manipal, India, 21-23 December 2017; EDP Sciences: Les Ulis, France, 2018; Volume 144, p. 02023.

36. Muasher, M.; Sain, M. The efficacy of photostabilizers on the color change of wood filled plastic composites. Polym. Degrad. Stab. 2006, 91, 1156-1165. [CrossRef]

37. Lu, K.; Ge, X.; Wei, Z.; Li, G.; Yang, X.; Liu, H. Synergistically enhanced ultraviolet aging resistance and interfacial adhesion of poly (p-phenylene benzobisoxazole) fiber with soluble naphthalimide sizing. Polym. Compos. 2021, 42, 2122-2134. [CrossRef]

38. Entelis, S.G.; Nesterov, O.V. Kinetics and mechanism of the reactions of isocyanates with compounds containing "active" hydrogen. Russ. Chem. Rev. 1966, 35, 917-930. [CrossRef]

39. Chamontin, K.; Lokshin, V.; Rossollin, V.; Samat, A.; Guglielmetti, R. Synthesis and reactivity of formyl-substituted photochromic 3, 3-diphenyl-[3H]-naphtho [2, 1-b] pyrans. Tetrahedron 1999, 55, 5821-5830. [CrossRef]

40. Haddad, R.A.; Alsayed, R.; Ahmed, D.S.; Bufaroosha, M.; Salih, N.; Mohammed, S.A.; Yousif, E. Environmental performance of coordination complexes as PVC photostabilizers. Mater. Today Proc. 2021, 42, 2849-2852. [CrossRef]

41. Cui, Z.H.; Xia, G.; Chen, W.G.; Jiang, H.; Yang, L.; Zuo, Z.W. Synthesis of novel multifunctional photostabilizers containing UVA and HALS moieties and their effects on polymers and dyes. J. Vinyl Addit. Technol. 2020, 26, 259-267. [CrossRef]

42. Zhao, X.; Wang, L.; Guo, L.; Ma, Y.; Wang, Z.; Niu, Q. The effect of a hindered amine light stabilizer on the aging behavior of moisture-curable polyurethane as a cultural relics consolidant. Polimery 2020, 65, 297-303. [CrossRef] 